Toru Goyagi MD, Makoto Tanaka MD, Toshiaki Nishikawa MD

\title{
Oral clonidine premed- ication reduces propofol requirement for laryngeal mask airway insertion
}

Purpose: To determine the effect of oral clonidine premedication on propofol requirement $\left(\mathrm{ED}_{50}\right)$ for the insertion of the laryngeal mask airway (LMA) in healthy patients undergoing abdominal hysterectomy.

Methods: After ethics committee approval and informed consent, 4 I patients were randomly assigned to receive $5 \mu \mathrm{g} \cdot \mathrm{kg}^{-1}$ clonidine po premedication 90 min before entering the operating room $(\mathrm{n}=22)$, or no clonidine $(\mathrm{n}=$ 19). To alleviate pain associated with iv propofol, $3 \mathrm{ml}$ lidocaine $2 \% \mathrm{iv}$ were administered. General anesthesia was induced, $30 \mathrm{sec}$ later, with propofol at a rate of $100 \mathrm{mg} \cdot \mathrm{min}^{-1}\left(600 \mathrm{ml} \cdot \mathrm{hr}^{-1}\right) \mathrm{iv}$. The dose of propofol at which insertion of the LMA was attempted was predetermined by modification of Dixon's up-and-down method with an initial dose of $2.5 \mathrm{mg} \cdot \mathrm{kg}^{-1}$ and $0.25 \mathrm{mg} \cdot \mathrm{kg}^{-1}$ as the step size. An LMA was inserted, without muscle relaxants or other adjuvants $90 \mathrm{sec}$ after completion of the propofol injection, by an anesthesiologist blinded to the treatment of the patient.

Results: The $\mathrm{ED}_{50}$ of propofol for LMA insertion in clonidine-treated patients $\left(2.0 \pm 0.2 \mathrm{mg} \cdot \mathrm{kg}^{-1}, 1.8-2.3\right.$ $\mathrm{mg} \cdot \mathrm{kg}^{-1}[95 \%$ confidence interval] $)$, was less than that in patients without clonidine $\left(2.5 \pm 0.1 \mathrm{mg} \cdot \mathrm{kg}^{-1}, 2.4-2.6\right.$ $\left.\mathrm{mg} \cdot \mathrm{kg}^{-1}, P<0.01\right)$.

Conclusion: Oral clonidine premedication reduces propofol requirement for LMA insertion.

Objectif: Déterminer l'effet d'une prémédication de clonidine orale sur les besoins en propofol (ED 50 ) lors de l'insertion du masque laryngé (ML) chez des patientes en santé qui subissent une hystérectomie abdominale.

Méthode : Après avoir obtenu l'accord du comité d'éthique et le consentement éclairé des participantes, 41 patientes ont été réparties au hasard et ont reçu une prémédication de $5 \mu \mathrm{g} \cdot \mathrm{kg}^{-1}$ de clonidine po $(\mathrm{n}=22), 90$ min avant d'entrer dans la salle d'opération, ou n'ont pas reçu de clonidine $(n=19)$. Pour soulager la douleur associée au propofol iv, on a administré $3 \mathrm{ml}$ de lidocaïne iv à $2 \%$. L'anesthésie générale a été induite, $30 \mathrm{~s}$ plus tard, avec du propofol à $100 \mathrm{mg} \cdot \mathrm{min}^{-1}\left(600 \mathrm{ml} \cdot \mathrm{h}^{-1}\right) \mathrm{iv}$. La dose de propofol à laquelle l'insertion du ML a été tentée était déterminée par une modification de la méthode en dents de scie de Dixon avec une dose initiale de 2,5 $\mathrm{mg} \cdot \mathrm{kg}^{-}$et des doses de $0,25 \mathrm{mg} \cdot \mathrm{kg}^{-1}$ comme palier. Un ML a été inséré, sans myorelaxant ou autre adjuvant, 90 $\mathrm{s}$ après l'injection de propofol par un anesthésiologiste impartial.

Résultats: $\mathrm{La} \mathrm{ED}_{50}$ de propofol pour l'insertion du ML chez les patientes traitées avec la clonidine $(2,0 \pm 0,2$ $\mathrm{mg} \cdot \mathrm{kg}^{-1} ;$ I,8-2,3 $\mathrm{mg} \cdot \mathrm{kg}^{-1}$ [intervalle de confiance de $95 \%$ ]), a été plus faible que chez les patientes sans clonidine $\left(2,5 \pm 0,1 \mathrm{mg} \cdot \mathrm{kg}^{-1} ; 2,4-2,6 \mathrm{mg} \cdot \mathrm{kg}^{-1}, P<0,0 \mathrm{l}\right)$.

Conclusion : La prémédication de clonidine orale réduit les besoins en propofol lors de l'insertion du ML.

From the Department of Anesthesia, Akita University School of Medicine, Hondo 1-1-1, Akita-shi, Akita-ken 010-8543, Japan. Address correspondence to: Dr. Makoto Tanaka, Phone: 81-18-884-6448; Fax: 81-18-884-6448; E-mail: mtanaka@med.akita-u.ac.jp Accepted for publication March 10, 2000. 


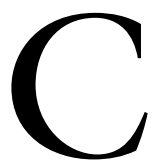

LONIDINE reduces induction time of sevoflurane, ${ }^{1}$ awakening concentrations of sevoflurane and isoflurane, ${ }^{1,2}$ and minimum alveolar concentration (MAC) of sevoflurane required for tracheal intubation. ${ }^{3}$ These findings suggest that clonidine may also reduce the anesthetic requirement for insertion of a laryngeal mask airway (LMA), which is often accomplished with propofol as the sole agent because of the more profound depression of upper airway reflexes and greater jaw relaxation that it produces in comparison with thiopental. ${ }^{4,5}$ This study was designed to test the hypothesis that oral clonidine reduces the amount of propofol required to insert an LMA in healthy patients.

\section{Method}

The protocol was approved by our ethics committee, and informed consent was obtained from each patient. Forty-one patients (25-61 yr), ASA I or II, undergoing total abdominal hysterectomy were studied. Patients were excluded if they were allergic to propofol, or had gastroesophageal, central nervous system, respiratory tract, or psychiatric disorders. They were randomized to clonidine group $(\mathrm{n}=22)$ receiving clonidine approximately $5 \mu \mathrm{g} \cdot \mathrm{kg}^{-1}$ plus $20 \mathrm{mg}$ famotidine po, or control group $(\mathrm{n}=19)$ receiving $20 \mathrm{mg}$ famotidine po, $90 \mathrm{~min}$ before arrival at the operating room. No other opioids or sedatives were given.

Standard monitoring including electrocardiography, noninvasive blood pressure and pulse oximetry were applied. Oxygen, $61 \cdot \mathrm{min}^{-1}$, was delivered via a face mask for three minutes before general anesthesia induction and was continued until an effective airway was established. To alleviate pain from iv propofol, 3 $\mathrm{ml}$ lidocaine $2 \%$ was first administered. Then, general anesthesia was induced in the supine position $30 \mathrm{sec}$ later with propofol at a rate of $100 \mathrm{mg} \cdot \mathrm{min}^{-1} i v$. A laryngeal mask airway (size \#3) was inserted without other adjuvants $90 \mathrm{sec}$ after completion of the propofol injection. The dose of propofol at which insertion of the LMA was attempted was predetermined by the response of the previous patient, using modification of Dixon's up-and-down method. ${ }^{6}$ The first patient in each group received $2.5 \mathrm{mg} \cdot \mathrm{kg}^{-1},{ }^{4}$ and the step size was $0.25 \mathrm{mg} \cdot \mathrm{kg}^{-1}$. All anesthetic management and insertions of the LMA were performed by a single anesthesiologist (TG) blinded to the patients treatment and propofol doses.

Patients response to the insertion of the LMA was described as "no movement" or "movement". "No movement" refers to the absence of bucking or gross purposeful muscular movements until an effective airway was established by confirming the square waveform
TABLE Estimated values of the coefficients of logit $(\mathrm{p} / \mathrm{l}-\mathrm{p})=\mathrm{B}_{0} \pm \mathrm{B}_{1 \mathrm{x}}$

\begin{tabular}{lll}
\hline & Clonidine group & Control group \\
\hline Intercept & -13.115 & -17.465 \\
Slope & 6.680 & 7.305 \\
Propofol dose & 1.963 & 2.391 \\
$P$ & 0.0236 & 0.0355 \\
\hline
\end{tabular}

Goodness of fit chi-squared clonidine group $=0.9208$; control group $=0.7264$.

$(\mathrm{P} / \underset{-1}{1-p})=\mathrm{B}_{0}+\mathrm{B}_{1 \mathrm{X}}, \mathrm{B}_{0}=$ intercept, $\mathrm{B}_{1}=$ slope, $\mathrm{X}=\mathrm{E} T_{\text {propofol }}$ $\left(\mathrm{mg} \cdot \mathrm{kg}^{-\mathrm{l}}\right.$.

of the capnograph, synchronous thoracoabdominal movement, and the absence of stridor. "Movement" refers to difficult mouth opening, gross purposeful movement, coughing, straining or laryngospasm before or after inflation of the LMA. ${ }^{7}$ If the patient "moved", the maneuver was stopped, and a further attempt was not made until $30 \mathrm{sec}$ after an additional injection of $0.5 \mathrm{mg} \cdot \mathrm{kg}^{-1}$ propofol. The presence or absence of movement was documented by the anesthesiologist (TG) and the nurse in charge of the case, who also remained blinded to the patients treatment and the propofol dose. When both observers documented any movement, the case was described as "movement". Each patient was tested for a single propofol dose.

The $\mathrm{ED}_{50}$ was estimated from calculating the midpoint dose of all independent pairs of patients involving a cross-over, i.e. "movement" to "no movement". The $\mathrm{ED}_{50}$ was defined as the average of the cross-over midpoints in each group. We have studied consecutive patients until six cross-over midpoints were obtained. Statistical analyses were performed using unpaired Student's t test, the probit test (SAS proprietary software, Chicago, IL), and a logistic regression test as appropriate. All values are expressed as mean $\pm S D$, and a $P$ value $<0.05$ was considered statistically significant.

\section{Results}

There were no differences in terms of age $(42 \pm 7$ vs $44 \pm 8 \mathrm{yr})$, weight $(53.7 \pm 8.6$ vs $55.1 \pm 9.1 \mathrm{~kg})$, or height ( $155 \pm 6$ vs $156 \pm 5 \mathrm{~cm}$ ) between the clonidine and control groups, respectively. The $\mathrm{ED}_{50}$ of propofol requirement in the clonidine group $(2.0 \pm 0.2$ $\left.\mathrm{mg} \cdot \mathrm{kg}^{-1}, 1.8-2.3 \mathrm{mg} \cdot \mathrm{kg}^{-1}[95 \% \mathrm{CI}]\right)$ was less than that in the control group $\left(2.5 \pm 0.1 \mathrm{mg} \cdot \mathrm{kg}^{-1}, 2.4-2.6\right.$ $\mathrm{mg} \cdot \mathrm{kg}^{-1}$, (Figure 1) $P=0.0013$ ). Logistic regression curves of the probability of no movement upon the LMA insertion in the clonidine and control groups are shown in Figure 2. Maximum likelihood estimators of the logistic regression model parameters and assess- 


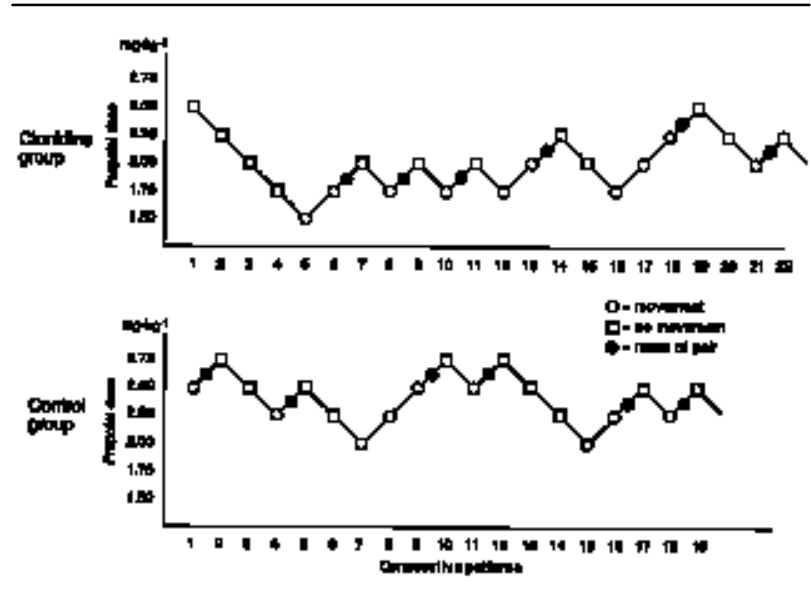

FIGURE 1 The responses of 22 (clonidine group) and 19 (control group) consecutive patients in whom laryngeal mask airway insertion was attempted, and the propofol dose. Patients are represented by an open circle and a square. Closed circles indicate the midpoint propofol doses of all independent pairs of patients involving a cross-over, i.e. "movement" to "no movement". The propofol doses required for smooth insertions of the laryngeal mask airway in the clonidine and control groups were $2.0 \pm 0.2$ and $2.5 \pm 0.1 \mathrm{mg} \cdot \mathrm{kg}^{-1}$, respectively.

ment of goodness of fit are presented in the Table. There were no differences between the observed and the predicted values in both groups. At LMA insertion, no patient developed $\mathrm{SpO}_{2}<97 \%$.

Discussion

Our results demonstrated that propofol requirement for the LMA insertion was reduced by oral clonidine premedication. Clonidine reduces the induction dose of propofol in adults, ${ }^{8} \mathrm{MAC}$ and induction time of sevoflurane in adults, ${ }^{1}$ MAC of sevoflurane required for tracheal intubation in children, ${ }^{3}$ and awakening concentrations of both sevoflurane and isoflurane in adults. ${ }^{1,2}$ The extent of reduction of these values ranged between 33 and $45 \%, 2,3,7,8$ while in our study propofol requirement was reduced by $20 \%$. These results suggest that clonidine premedication, merely for reducing the propofol requirement, does not seem to be clinically relevant, although clonidine may provide other benefits, such as intraoperative hemodynamic stability, and potentiation of postoperative analgesic regimen.

One may argue that we used lidocaine before propofol injection to reduce pain from $i v$ propofol. Lidocaine, $1.5 \mathrm{mg} \cdot \mathrm{kg}^{-1}$, reduces coughing, airway obstruction and incidence of failure in LMA insertion. ${ }^{9}$ Thus, the use of lidocaine before propofol may

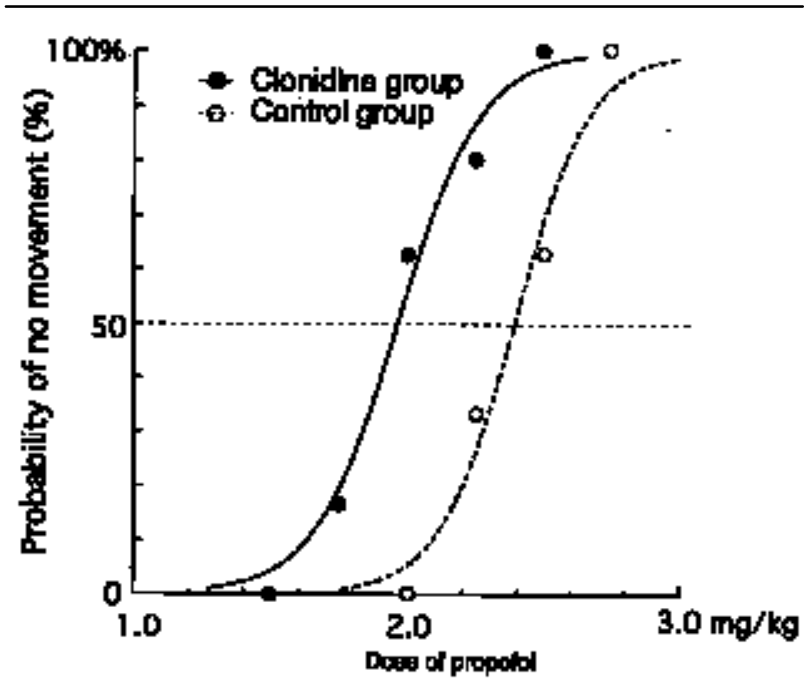

FIGURE 2 Dose-response curves for propofol plotted from logit analyses of individual propofol doses and the respective reactions to laryngeal mask airway insertions with or without clonidine premedication.

have resulted in underestimation of the ED50 of both groups. Second, although no patient developed hypotension or bradycardia at induction, clonidine alone or in combination with propofol may produce hemodynamic perturbations in the elderly. Finally, there was a wide range in patient age in our study. However, MAC required for LMA insertion in the elderly $(65-90 \mathrm{yr})$ is similar to that of young adults $(18-50 \mathrm{yr}),{ }^{10}$ suggesting that sensitivity of pharynx to mechanical stimulation may not be age-related.

In conclusion, oral clonidine reduces propofol requirement for smooth insertion of the LMA in healthy surgical patients.

\section{References}

1 Inomata $S$, Yaguchi $\Upsilon$, Toyooka $H$ The effects of clonidine premedication on sevoflurane requirements and anesthetic induction time. Anesth Analg 1999; 89: 204-8.

2 Goyagi T, Tanaka M, Nishikawa T. Oral clonidine premedication reduces the awakening concentration of isoflurane. Anesth Analg 1998; 86: 410-3.

3 Nishina K, Mikawa K, Shiga M, Maekawa N, Obara $H$. Oral clonidine premedication reduces minimum alveolar concentration of sevoflurane for tracheal intubation in children. Anesthesiology 1997; 87: 1324-7.

4 Blake DW, Dawson P, Donnan G, Bjorksten A. Propofol induction for laryngeal mask airway insertion: dose 
requirement and cardiorespiratory effects. Anaesth Intensive Care 1992; 20: 479-83.

5 McKeating K, Bali IM, Dundee JW. The effects of thiopentone and propofol on upper airway integrity. Anaesthesia 1988; 43: 638-40.

6 Dixon WJ. Quantal response to valuable experimentation: the up-and-down method. In: McArthur JW, Colton T (Eds.). Statistics in Endocrinology.

Cambridge: MIT Press, 1967: 251-64.

7 Taguchi M, Watanabe S, Asakura N, Inomata S. Endtidal sevoflurane concentrations for laryngeal mask airway insertion and for tracheal intubation in children. Anesthesiology 1994; 81: 628-31.

8 Goyagi T, Tanaka M, Nishikawa T. Oral clonidine premedication reduces induction dose and prolongs awakening time from propofol-nitrous oxide anesthesia. Can J Anesth 1999; 46: 894-6.

9 Stoneham MD, Bree SE. Facilitation of laryngeal mask insertion. Effects of lignocaine given intravenously before induction with propofol. Anaesthesia 1995; 50: 464-6.

10 Tanaka M, Watanabe S, Nishikawa T. Minimum alveolar sevoflurane concentrations required for insertion of the cuffed oropharyngeal airway and the laryngeal mask airway: a comparative study. Anaesthesia 1999; 54: 1155-60. 